\title{
Establishment of regional background for heavy metals in the soils of the Lower Don and the Taganrog Bay coast
}

\author{
Elizaveta Konstantinova*, Tatiana Minkina, Dina Nevidomskaya, Tatiana Bauer, \\ Yuri Fedorov, Inna Zamulina, Saglara Mandzhieva, Natalia Kravtsova, Marina Voloshina, \\ Tamara Dudnikova, and Aleksey Shcherbakov
}

Southern Federal University, 344006 Rostov-on-Don, Russian Federation

\begin{abstract}
Data on the regional geochemical background and threshold values of heavy metals are required to establish anomalies and assess soil pollution. As a rule, the background values are the average contents of elements in natural undisturbed soils, or the threshold values for the study area, obtained by statistical methods. The aim of the study is to obtain geochemical threshold values of heavy metals in the soils of the Lower Don and the Taganrog Bay coast using different statistical approaches. A total of 86 topsoil samples were collected from the study area. The concentrations of $\mathrm{Cr}, \mathrm{Mn}, \mathrm{Ni}, \mathrm{Cu}, \mathrm{Zn}, \mathrm{As}, \mathrm{Cd}$, and $\mathrm{Pb}$ were analyzed by $\mathrm{X}-$ ray fluorescence. The median element concentrations in the soils of the study area were consistent with world soil average and metal concentrations in background soils of protected area. Using a 'geochemical' approach is not suitable for this dataset because it does not take into account the natural variability of concentrations in different soil types. The Tukey inner fence method delivers estimates that do not detect outliers for $\mathrm{Ni}$, $\mathrm{As}, \mathrm{Cd}$, and $\mathrm{Pb}$. The 'median +2 median absolute deviations' method was the most appropriate, as it consistently provided the most conservative background values.
\end{abstract}

\section{Introduction}

The floodplain of the Lower Don and the Taganrog Bay coast are territories with a high population density, intensive agriculture, developed industry and transport infrastructure. Intense anthropogenic impact in this region leads to the entry into the soil of a significant amount of pollutants, including heavy metals (HM), which pose a potential hazard to public health and environmental quality [1-3].

Since HMs enter soils from both natural and anthropogenic sources, it is necessary to establish a 'normal' range of the contents of individual elements, reflecting the heterogeneity of the environment [4]. Knowledge of background values of HM in soils is necessary for a soil pollution assessment. The threshold value separates the background values from the abnormal ones; otherwise, it is the upper threshold of the natural range [5].

\footnotetext{
${ }^{*}$ Corresponding author: konstantliza@gmail.com
} 
There are two main groups of methods for determining the background values of metals in soils, namely 'geochemical' and 'statistical' ones [6]. The first approach involves the use of a natural background corresponding to the average content of elements in natural unchanged soils [4-5]. The "statistical" approaches approximate the ambient geochemical baseline based on soil samples collected in each area [6]. The most widely used method for geochemical threshold determination is the calculation of the 'mean +2 standard deviations' ('mean $+2 \mathrm{SD}$ '), that requires a normal distribution and independence of the sampling points [7]. Reimann et al. [5] suggested replacement of the 'mean+2SD' with the nonparametric approach of the 'median +2 median absolute deviations' ('med+2MAD') as a much more robust method against the effect of data outliers, especially for data with skewed distribution [8-9]. In geochemical mapping is widespread the Tukey inner fence (TIF) ('upper whisker' method), consisted in using the upper whisker of a Tukey's box plot $[7,9]$. The average concentrations of HMs in the Fluvisols of the Chumbur-Kosa protected area [10] were used as a natural geochemical reference. However, the 'geochemical' approach to determining the background values assumes that the compared soils are similar to the background ones in terms of their physicochemical properties and are formed in similar landscape conditions.

This study aims to 1) determine the levels of of $\mathrm{Cr}, \mathrm{Mn}, \mathrm{Ni}, \mathrm{Cu}, \mathrm{Zn}, \mathrm{As}, \mathrm{Cd}$, and $\mathrm{Pb}$ in soils of the Lower Don and the Taganrog Bay coast, 2) evaluate regional geochemical threshold values for HMs, and 3) compare the statistically derived threshold values with the concentrations of HMs in soils of protected area.

\section{Materials and Methods}

\subsection{Study area and soil sampling}

The study area is located within the Lower Don and the Taganrog Bay coast, which is the largest Bay of the Azov Sea (Fig. 1). The adjacent territory can be subdivided into Northern Pryazovia region of Pliocene-Pleistocene plains with intensive gully erosion, Eastern Pryazovia region of accumulative Pliocene-Pleistocene plains with lower intensity of erosional processes and the Lower Don of fluvial terraces and floodplains [11]. The climate of the territory is continental with an average temperature of $9.9^{\circ} \mathrm{C}$, and the mean yearly precipitation of $615 \mathrm{~mm}$. The most common landscapes of the study area are coppice willows, floodplain meadows, sand dunes, beaches and spits, parks, gardens and other tree plantations, urbanized and industrial areas. The most common soils are Fluvisols.

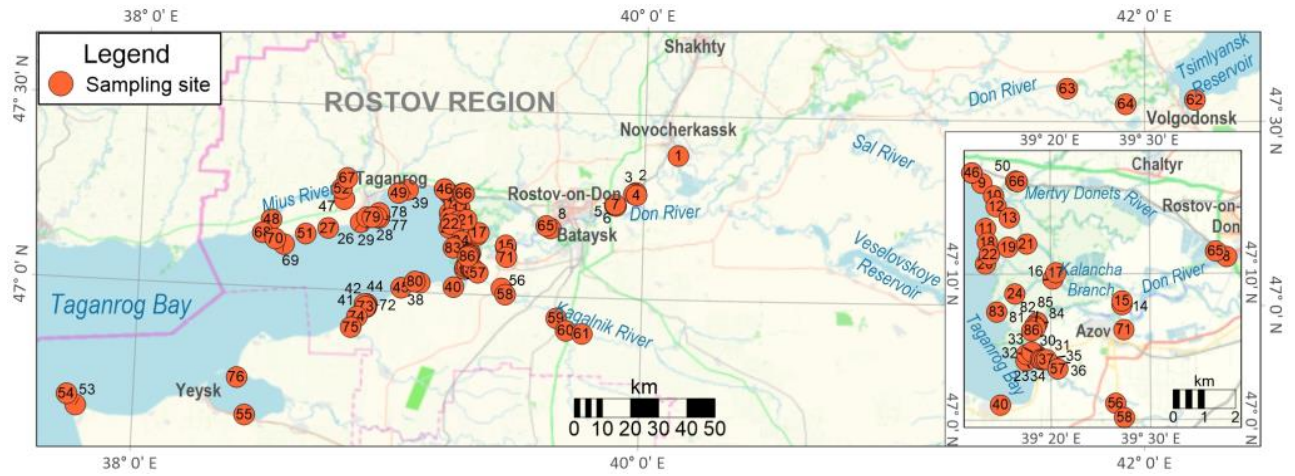

Fig. 1. Location of sampling sites of surface soils of the Lower Don and the coastal zone of the Taganrog Bay (base map from www.openstreetmap.org). 


\subsection{Soil sampling and analytical methods}

Total of 86 soil samples (Fig. 1) were collected in summer 2020 from a depth of 0-20 cm. The soil samples were air-dried, mixed, ground, and passed through a 1-mm sieve [12]. The total concentrations of $\mathrm{Cr}, \mathrm{Mn}, \mathrm{Ni}, \mathrm{Cu}, \mathrm{Zn}, \mathrm{Cd}$, and $\mathrm{Pb}$ were determined by X-ray fluorescence analysis using a Spectroscan MAX-GV spectrometer (Spectron, Russia) [13]. All laboratory tests were performed in triplicate. The accuracy of element determination was verified using duplicates, reagent blanks, and state standard reference samples and complies with standards of certified methods [13]. The recovery rates and quantification range for the metals were based on the standard certificate.

\subsection{Determination of geochemical threshold values}

The software package STATISTICA 12 (StatSoft, USA) was used to analyze data. Basic descriptive statistics included mean, median, minimum, maximum, standard deviation (SD), and coefficient of variation (CV) for HM concentrations. The normal distribution of the data was checked by Kolmogorov-Smirnov test.

Geochemical background concentrations of HMs in topsoils of studied region were defined using three alternative approaches: 'mean $+2 \mathrm{SD}$ ', 'med +2 MAD' and TIF. The 'mean + 2 SD' was used based on the assumption that all values beyond 'mean $+2 \mathrm{SD}$ ' are omitted from the dataset and the new 'mean $+2 \mathrm{SD}$ ' range is calculated using the reduced data. This procedure is repeated until all the values of the dataset lie within the range approaching a normal distribution $[5,7]$.

The correct approach to using 'med +2 MAD' would thus be to calculate threshold value on the log-transformed data (e.g., using log base 10) and to then back-transform the result and use these values as threshold according to the formula [9]:

$$
\text { Threshold }=10^{\wedge}\left(\text { median }_{i}\left[\log _{10}\left(x_{i}\right)\right]+2\left\{\text { median }_{i}\left|\log _{10}\left(x_{i}\right)-\operatorname{median}_{j}\left[\log _{10}\left(x_{j}\right)\right]\right|\right\}\right)
$$

The TIF is calculated following a log-transformed of the data and subsequent backtransformation using the formula [8]:

$$
T I F=Q 3+1.5 I Q R
$$

where Q3 stands for the 3rd quartile (equivalent to the 75th percentile), and IQR is the inter quartile range ( 75 th -25 th percentile).

\section{Results and Discussion}

\subsection{Levels of HMs in soils}

Table 1 summarizes the descriptive statistics for eight HMs identified in the soil samples. The mean concentrations of $\mathrm{Mn}, \mathrm{Zn}, \mathrm{Cd}$, and $\mathrm{Pb}$ were significantly higher than their median values, indicating a right-skewed distribution bias. The distribution of all HMs (except of As) differs from the normal distribution according to the Kolmogorov-Smirnov test ( $\mathrm{p}<$ 0.05). Consequently, the median values of the elements better characterize the central tendency of the distribution. The metals, in descending order of median concentration, were $\mathrm{Mn}, \mathrm{Cr}, \mathrm{Zn}, \mathrm{Ni}, \mathrm{Cu}, \mathrm{Pb}$, As, and $\mathrm{Cd}$. The median contents of $\mathrm{Cd}$ and $\mathrm{Cr}$ were 1.8 and 1.6 times higher than the world soil average [14], and the contents of $\mathrm{Mn}, \mathrm{Zn}, \mathrm{Ni}, \mathrm{Cu}, \mathrm{Pb}$, and As were comparable to the global geochemical background. The median content of HMs in the soils of the study area was consistent with that identified in the Fluvisols of the Chumbur-Kosa protected area [10], with the exception of cadmium (3.7 times excess). 
Table 1. Descriptive statistics of heavy metals concentrations (mg kg-1) in topsoils from the Lower Don and the Taganrog Bay coast $(n=86)$.

\begin{tabular}{|c|c|c|c|c|c|c|}
\hline Element & Mean & Median & Minimum & Maximum & SD & CV \\
\hline $\mathrm{Cr}$ & 97.8 & 93.9 & 34.1 & 297.0 & 44.3 & 45.3 \\
\hline $\mathrm{Mn}$ & 843.8 & 723.9 & 202.3 & 2466.2 & 390.7 & 46.3 \\
\hline $\mathrm{Ni}$ & 45.8 & 43.9 & 19.0 & 98.0 & 17.9 & 39.1 \\
\hline $\mathrm{Cu}$ & 42.5 & 40.4 & 4.1 & 106.9 & 17.3 & 40.8 \\
\hline $\mathrm{Zn}$ & 120.7 & 92.0 & 30.2 & 631.5 & 94.7 & 78.5 \\
\hline $\mathrm{As}$ & 7.7 & 7.6 & 1.1 & 18.2 & 3.9 & 50.2 \\
\hline $\mathrm{Cd}$ & 1.42 & 0.74 & 0.10 & 6.21 & 1.44 & 101.3 \\
\hline $\mathrm{Pb}$ & 38.8 & 32.3 & 5.3 & 129.6 & 24.9 & 64.1 \\
\hline
\end{tabular}

Concentrations of HMs in soils of the Lower Don and the Taganrog Bay coast varied considerably, reflecting both the heterogeneity of ecological factors and the diversity of their anthropogenic sources (Table 1). The highest SD and CV were characteristics of Cd, which indicates its anthropogenic origin. High SD and CV values were identified for Zn, $\mathrm{As}$, and $\mathrm{Pb}$, and moderate values for $\mathrm{Cr}, \mathrm{Mn}, \mathrm{Ni}$, and $\mathrm{Cu}$. Therefore, the input into the soils of the first group of HMs was probably associated with the significant anthropogenic sources, while the metals of the second group are mainly controlled by natural factors.

\subsection{Comparison of derived geochemical threshold values}

The calculated threshold values of HMs in the soils of the Lower Don and the Taganrog Bay coast are presented in Table 2. In addition, the world soil average [14] and the background concentrations of HMs in Fluvisols of the Chumbur-Kosa protected area [10] are listed in Table 2.

Obviously, the threshold values of HMs obtained for the soils of the Lower Don and Taganrog Bay were higher than the world soil average and the content of metals in natural background soils. World soil averages illustrate the central trend, that is, the most "typical" values of the elements. The natural background of elements is an absolute value, determined for a specific type of soil and did not take into account the natural abundance of elements in various landscape conditions characteristic of the territory. When using the global and regional geochemical background, an unjustifiably large number of samples fell into the category of 'anomalous' in terms of the content of elements (Table 2).

Values from 'med +2 MAD' method gave the lowest background limit; followed by the 'mean + 2SD', while the TIF method produced the highest background limits. The proportion of samples exceeding the different threshold values for the 8 elements are shown in Table 2. The TIF method did not reveal anomalies of $\mathrm{Ni}, \mathrm{As}, \mathrm{Cd}$, and $\mathrm{Pb}$ in the soils of the study area, which is associated with the narrow data distributions. This feature of the method was noted in other studies [9]. The results of 'med +2 MAD' approach were the most 'conservative' and provided the highest proportion of sites needing attention from the point of view of protection of the environment and human health. 
Table 2. Geochemical threshold values for 8 heavy metals in topsoils from the Lower Don and the Taganrog Bay coast.

\begin{tabular}{|c|c|c|c|c|c|c|c|c|c|c|}
\hline \multirow{2}{*}{ Metal } & \multicolumn{4}{|c|}{ Threshold values (mg kg-1 } & \multicolumn{3}{c|}{ \% of samples above the threshold } \\
\cline { 2 - 12 } & $\begin{array}{c}\text { Mean + } \\
\text { 2 SD }\end{array}$ & $\begin{array}{c}\text { Med + 2 } \\
\text { MAD }\end{array}$ & TIF & $\begin{array}{c}\mathbf{G B}^{\mathbf{1}} \\
{[\mathbf{1 4}]}\end{array}$ & $\begin{array}{c}\mathbf{N B}^{\mathbf{2}} \\
{[\mathbf{1 0}]}\end{array}$ & $\begin{array}{c}\text { Mean + } \\
\text { 2 SD }\end{array}$ & $\begin{array}{c}\text { Med + } \\
\text { 2MAD }\end{array}$ & TIF & GB & NB \\
\hline $\mathrm{Cr}$ & 135.1 & 124.9 & 164.2 & 59.5 & 95 & 8.1 & 10.5 & 5.8 & 87.2 & 46.5 \\
\hline $\mathrm{Mn}$ & 1339.5 & 1139.1 & 1906.5 & 488 & 720 & 11.6 & 18.6 & 2.3 & 90.7 & 52.3 \\
\hline $\mathrm{Ni}$ & 81.7 & 80.8 & 142.5 & 29 & 35 & 4.7 & 5.8 & 0.0 & 81.4 & 65.1 \\
\hline $\mathrm{Cu}$ & 64.6 & 57.1 & 81.3 & 38.9 & 45 & 10.5 & 11.6 & 5.8 & 53.5 & 30.2 \\
\hline $\mathrm{Zn}$ & 190.8 & 168.6 & 374 & 70 & 71 & 15.1 & 17.4 & 2.3 & 70.9 & 70.9 \\
\hline $\mathrm{As}$ & 15.5 & 15.2 & 22.8 & 6.8 & - & 4.7 & 5.8 & 0.0 & 59.3 & - \\
\hline $\mathrm{Cd}$ & 3.4 & 2.8 & 16.6 & 0.41 & 0.2 & 10.5 & 14.0 & 0.0 & 81.4 & 95.3 \\
\hline $\mathrm{Pb}$ & 75.2 & 82.7 & 217.1 & 27.0 & 26 & 8.1 & 3.5 & 0.0 & 61.6 & 64.0 \\
\hline
\end{tabular}

${ }^{1}$ Global background; ${ }^{2}$ Natural background

\section{Conclusions}

The soils from the Lower Don and the Taganrog Bay coast are characterized by enrichment of $\mathrm{Cd}$ and $\mathrm{Cr}$ in comparison with the global geochemical background. The median content of HMs in the soils of the study area was consistent with the natural background concentrations in soils from protected area. However, the 'geochemical' approach was not suitable for deliver useful threshold values, since it will not be able to separate pollution from naturally elevated HMs concentrations.

Geochemical threshold values derived by different statistical methods allow to identify the location of priority areas for future protection. Comparative analysis showed that the best method was 'med +2 MAD'. Estimated background values determined with this approach yields $124.9 \mathrm{mg} \mathrm{kg}^{-1}$ for $\mathrm{Cr}, 1139.1 \mathrm{mg} \mathrm{kg}^{-1}$ for $\mathrm{Mn}, 80.89 \mathrm{mg} \mathrm{kg}^{-1}$ for Ni, $57.19 \mathrm{mg} \mathrm{kg}^{-1}$ for $\mathrm{Cu}, 168.69 \mathrm{mg} \mathrm{kg}^{-1}$ for $\mathrm{Zn}, 15.29 \mathrm{mg} \mathrm{kg}^{-1}$ for As, $2.89 \mathrm{mg} \mathrm{kg}^{-1}$ for $\mathrm{Cd}$, and $82.79 \mathrm{mg}$ $\mathrm{kg}^{-1}$ for $\mathrm{Pb}$, respectively.

The reported study was funded by Russian Science Foundation, project number 20-14-00317.

\section{References}

1. T.M. Minkina, Y.A. Fedorov, D.G. Nevidomskaya, T.N. Pol'shina, S.S. Mandzhieva, V.A. Chaplygin, Eurasian Soil Sci. 50, 1033-1047 (2017)

2. T.M. Minkina, D.G. Nevidomskaya, T.N. Pol'shina, Y.A. Fedorov, S.S. Mandzhieva, V.A. Chaplygin, T.V. Bauer, M.V. Burachevskaya, J. Soil. Sediment. 17, 1474-1491 (2017)

3. T. Minkina, G. Fedorenko, D. Nevidomskaya, E. Konstantinova, T. Pol'shina, A. Fedorenko, V. Chaplygin, S. Mandzhieva, T. Dudnikova, T. Hassan, Water 13(2), 227 (2021)

4. C. Reimann, R.G. Garret, Sci. Total Environ. 350, 12-27 (2005) 
5. C. Reimann, P. Filzmoser, R.G. Garrett, Sci. Total Environ. 346, 1-16 (2005)

6. B. Labaz, C. Kabala, J. Waroszewski, Environ. Monit. Assess. 191, 19 (2019)

7. P. Tume, E. González, R.W. King, V. Monsalve, N. Roca, J. Bech, J., Geochem. Explor. 184B, 333-344 (2018)

8. C. Reimann, P. de Caritat, Sci. Total Environ. 578, 633-648 (2017)

9. C. Reimann, K. Fabian, M. Birke, P. Filzmoser, A. Demetriades, P. Négrel, K. Oorts, J. Matschullat, P. de Caritat, Appl. Geochem. 88, 302-318 (2018)

10. T. M. Minkina, D. G. Nevidomskaya, T. N. Pol'shina, Yu. A. Fedorov, S. S. Mandzhieva, V. A. Chaplygin, T. V. Bauer, M. V. Burachevskaya, J. Soils Sediment. 17, 1474-1491 (2017)

11. R.D. Kosyan, M.V. Krylenko, Modern state and dynamics of the sea of Azov coasts. Estuar. Coast. Shelf S. 224, 314-323 (2019)

12. L.A. Vorobyova, Theory and practice of chemical analysis of soils (GEOS, Moscow, 2006)

13. OST 10-259-2000, Soil. X-ray fluorescence determination of the total content of heavy metals (The Russian Federation Ministry of Agriculture Moscow, 2001)

14. A. Kabata-Pendias, Trace elements in soils and plants, fourth ed. (CRC Press, Boca Raton, 2011) 